\title{
Impact of the COVID-19 Pandemic on Instagram and Influencer Marketing
}

\author{
Evelina Francisco ${ }^{1}$, Nadira Fardos ${ }^{1}$, Aakash Bhatt ${ }^{1} \&$ Gulhan Bizel $^{1}$ \\ ${ }^{1}$ Frank J. Guarini School of Business, Saint Peter's University, Jersey City, New Jersey, US \\ Correspondence: Gulhan Bizel, Frank J. Guarini School of Business, Saint Peter's University, 2641 John. F. \\ Kennedy Blvd, Jersey City, New Jersey, US.
}

Received: February 10, $2021 \quad$ Accepted: April 8, $2021 \quad$ Online Published: May 13, 2021

doi:10.5539/ijms.v13n2p20 URL: https://doi.org/10.5539/ijms.v13n2p20

\begin{abstract}
The COVID-19 pandemic and the resulting stay-at-home orders have disrupted all aspects of life globally, most notably our relationship with the internet and social media platforms. People are online more than ever before, working and attending school from home and socializing with friends and family via video conferencing. Marketers and brands have been forced to adapt to a new normal and, as a result, have shifted their brand communication and marketing mix to digital approaches. Hence, this study aims to examine the shift of influencer marketing on Instagram during this period and the possible future implications. By employing an online survey for exploratory research, individuals answered questions addressing their perceptions about the impact of the pandemic, brands and influencers' relationship, and the overall changes made in marketing strategy.
\end{abstract}

Keywords: instagram, branding, brands, instagram influencers, influencer marketing, COVID-19 pandemic

\section{Introduction}

The unprecedented integration of social media into people's lives has provided brands with ample opportunity to connect with consumers. As a result, social media has revolutionized brand communications and has caused a significant shift from a contact to a conversational model (Dias et al., 2020). Among many new approaches, influencer marketing has emerged as a successful approach to connect with potential customers on social media (Campbell \& Farrell, 2020). Similarly, marketers are using social media, particularly their partnerships with social media influencers, to engage with consumers and draw interest in their goods and services (Campbell \& Farrell, 2020). Social media influencers are defined as prominent users on the various platforms who accumulated a large and dedicated following by crafting authentic online personas (Tafesse \& Wood, 2020). According to (Ki et al., 2020), influencer marketing has become an integral part of digital marketing strategies under the premise that this marketing method is useful in yielding higher profits. This belief can be attributed to the overwhelming positive perception of influencers by their followers, which renders the messaging highly effective in soliciting a desired response (Tafesse \& Wood, 2020).

\subsection{Impact of COVID-19 Pandemic on Marketing}

The COVID-19 pandemic and the resulting harsh economic consequences of the measures taken to mitigate the spread, such as lockdowns, social distancing restrictions, indoor and outdoor capacity limitations, drastically changed lives across the globe (Enberg, 2020). The restrictions and limitations to free movement caused by the pandemic have forced the economy from a total standstill to a slow recovery (Enberg, 2020). Facing unprecedented challenges and a "new normal", the marketing industry has adopted methods to overcome communication and engagement gaps with their target audiences (Enberg, 2020). With most of the world's population at home, social media platforms have become a means for keeping in touch with friends and family and interacting with brands (Dias et al., 2020). During this period, brands have chosen social media to remain relevant and continue to build brand awareness while helping consumers cope by offering positive messaging to overcome the difficulties of this moment (Dias et al., 2020). Furthermore, Instagram has emerged as a prominent and constant presence in the daily lives of young people, so it is no surprise that brands, perceiving this tendency, increasingly seek to communicate through the platform (Dias et al., 2020).

Instagram is a social media platform that allows users to share snapshots of moments with other followers. In 
research from Campbell and Farrell (2020), several brands and influencers were found to have built strong relationships with their followers on Instagram. The COVID-19 pandemic has dramatically changed how people live and communicate (Dias et al., 2020). Many brands have had to change their marketing strategies to adapt to brand communication through various social media platforms (Enberg, 2020). Brands have used social media platforms such as Instagram to keep in touch with followers, spread information, make donations, and produce sanitization products and masks (Dias et al., 2020). Instagram is a platform that has a high level of engagement between a brand and influencer to its followers (Maares et al., 2020). The platform serves as a way for brands to build strong and long-term relationships with their customers, spread positive word of mouth, and increase brand awareness (Casaló et al., 2020). Instagram is also a great tool for the users that follow brands because it inspires them and it gives the user the ability to engage with other users (Dias et al., 2020).

\subsection{Literature Review}

New technologies, in combination with new ways of interaction, are changing consumer consumption. We see an overall shift in marketing trends and the perceived value of digital strategies across all industries (Arora et al., 2019). Over the last five years, social media has profoundly shifted the market. Consumers have grown accustomed to a global market that provides immediate satisfaction while nurturing a closer relationship with brands (Arora et al., 2019). It is now a common practice for brands to use Instagram to share content that enhances brand awareness and promotes and propagates community (Casaló et al., 2020). With visual and aesthetic components, Instagram has emerged as a useful tool for brands in fashion, design, travel, hospitality, retail, and more (Dias et al. 2020). According to a study from Ha et al., (2019) results showed that two dimensions of mental imagery have a positive effect on the quality and elaboration towards a brand's social network service. The platform offers an advantage applying a visual strategy that provides the capacity for greater user involvement while reaching a much larger and responsive audience at a lower cost (Phua et al., 2017). It is a very effective channel to build a strong and lasting relationship with your audience, reach prospective audiences, and create positive electronic word of mouth (eWOM) advertising (Dhanesh \& Duthler, 2019). The presence of brands and visual storytelling on this platform is also important to create a sense of community and belonging (Dhanesh \& Duthler, 2019). In online brand communities' users share views and fulfill their social and identification needs (Phua et al., 2017). Users get the opportunity to participate and engage in ways that were not previously possible (Dia, et al., 2020).

\subsubsection{Instagram and Influencer Marketing}

Instagram and influencers are key to building brand awareness and staying relevant to millions of users around the world (Casaló et al., 2020). Instagram influencers forge a personal relationship and bond with their followers by crafting a genuine online persona by sharing personal content (Tafesse $\&$ Wood, 2020). Instagram marketing can be highly effective for users who have a positive perception of the influencers that they follow (Tafesse \& Wood, 2020). This would create the desired impact that the brand wants because the brand is leveraging the trust and connection between the influencer and follower (Tafesse \& Wood, 2020). Instagram allows users to post photos or videos, add captions, use hashtags, like and comment on photos or videos, and create and highlight stories on the users' feed (Casaló et al., 2020). According to Phua et al., (2017), Instagram users scored highest for showing affection and demonstrating sociability. In this study, Instagram users also scored the highest brand community engagement and commitment. When users feel like they belong and commit to a brand community they have a higher intention to purchase from the brand (Phua et al., 2017).

As a social media platform, Instagram has evolved from a single social purpose to a powerful marketing tool (Djafarova \& Bowes, 2020). The platform is now a key marketing component in most digital strategies (Ki et al., 2020). With more than 1 billion monthly active users across all ages and genders, an estimated 4.2 billion posts, and 400 million stories per day, Instagram has achieved an incredible global reach (Djafarova \& Bowes, 2020). Marketing strategies on Instagram consists of three pillars: content, community management, and viral marketing (Dias et al., 2020). Because of the platform's nature, users are typically more attracted and engaged with more entertaining or exciting content (Casaló et al., 2020). Over time, incorporating new features such as stories, live videos, reels, and more has led to improved user experience, further expanding its reach (Ki et al., 2020). The platform has also given brands the ability to tag images of products to sell directly to followers (Djafarova \& Bowes, 2020). Adding this new service not only has allowed simplification at checkout but has also become a potent stimulator in impulse purchases (Djafarova \& Bowes, 2020).

Pre-pandemic, brands used influencers to create brand awareness on Instagram (Campbell \& Farrell, 2020). Influencers play a pivotal role in the social media landscape and influence marketing (Dias et al., 2020). Influencer marketing involves leveraging the trust and connection that influencers have built with their followers 
to extend brands' reach and impact on social media. Influencer marketing is a type of hidden advertising similar to native advertising in that paid content is made to look organic. While this has immense benefits for sponsoring brands, it is a double-edged sword due to the possibility of deceiving followers, who might mistake paid content for genuine, unpaid posts (Dhanesh \& Duthler, 2019). While consumers generally appreciate the less interruptive nature of this type of advertising, there's a possibility of negative reactions if followers are made aware of its covert intent (Dhanesh \& Duthler, 2019).

According to Argyris et al. (2020), Influencers are just ordinary individuals, not celebrities, who have compiled many followers on social media sites by posting visually attractive content that showcases their lifestyle and merchandise preferences. Influencers typically post-self-centric selfies, appealing group photos, glamorous portraits taken by others, product/brand photos (style, beauty, travel, interior, and food.), and often post photos wearing the products, which persuades viewers at large (Jin et al., 2020). This type of marketing relies on the positive perception of influencers by followers, which renders their messaging highly effective, creating the desired brand impact (Tafesse \& Wood, 2021). In research from Tafesse and Wood (2021), 42\% of the marketers reported using influencer marketing as their always-on strategy instead of a one-off, tactical campaign. The market size of influencer marketing worldwide reached 148 million in 2019, an 8\% increase from 2018, and this number is expected to exceed $\$ 373$ million by 2027 (Tafesse \& Wood, 2021). Brands that want to maximize the significant benefits influencer marketing can offer most identify suitable partners with a hoard number of followers and have acquired potential to influence them (Campbell \& Farrell, 2020).

\subsubsection{Influencer Marketing During COVID-19 Pandemic}

With consumers cooped up at home, marketers have been forced to adapt and expand online marketing strategies (Enberg, 2020). The study conducted by Dias et al. (2020) revealed that most brands were confronted with challenges to market and rethink strategies to remain relevant for their consumers while contributing to coping with the pandemic. The pandemic has also disrupted the influencer marketing industry, with most influencers having to address the challenge of creating organic and authentic content while still promoting brands (Enberg, 2020). As noted in Enberg (2020), budgets have been significantly reduced, resulting in brands having less money to spend on digital marketing. The lack of available funds has also impacted the willingness of influencers to partner with brands for free (Enberg, 2020). As the pandemic continues, influencers and brands have started to shift their communication away from products and services and more toward values (Enberg, 2020). Brand turned to trusted advocates, giving them creative control to add value to people's new realities (Enberg, 2020). These trends are not new; they have simply accelerated pre-pandemic changes such as more organic and authentic content and the rise of "everyday influencer" (Enberg, 2020).

\subsection{Importance of Research}

The recent literature on this topic focuses on the use and efficacy of influencers and influencer marketing for brands. Brands have had to expand their way of connecting with current customers and potential customers (Dhanesh \& Duthler, 2019). They have started to focus more on communication and demonstrating what their values are (Dhanesh \& Duthler, 2019). This form of marketing helps the brand and influencer remain relevant and popular with its customers and followers (Ha et al., 2019). Within this research, stakeholders such as the users, brands, marketing agencies, and influencers will understand this form of marketing's positive and negative aspects (Dias et al., 2020). Influencers act as opinion leaders because followers tend to trust them more than brands by comparison (Ki et al., 2020). Influencers are perceived to share more intimacy with their followers, which makes them feel more valued (Casaló et al., 2020). Customers now have new ways of keeping updated on these brands and are provided with exclusive deals to purchase (Dhanesh \& Duthler, 2019).

The use of Instagram and influencer marketing is not a new form of marketing, but it has become more prevalent during the recent year of the COVID-19 pandemic (Dias et al. 2020). This advertising type has become a way for brands to build brand awareness and continue to actively promote their products and services with influencers aligned with their targeted audience and value (Casaló et al., 2020). This research helps gain a better understanding of this form of marketing's effectiveness by providing a deeper understanding of the pandemic's impact. Thus, this study sets to:

1) Investigated the impact of influencer marketing on Instagram users during the pandemic.

2) Identified the key challenges faced by influencers and future marketing trends that may have resulted from changes in lifestyles due to the pandemic.

3) Examined the role of influencer and brand content-driven attributes and their effects on their followers.

This study's findings will help understand the role of the influencer and brand content and how effective it is to 
convert followers into loyal customers and purchase these products or services that are being promoted, and the importance of brand communications during times of uncertainty or crises.

\section{Methodology}

To answer the research questions and collect primary data, an online survey was created and distributed to the general public. The survey was administered on social media platforms (Instagram, Facebook \& LinkedIn), survey exchange sites (SurveySwap \& PollPool), and sent to individuals 18 years and older that use Instagram frequently via email. The survey was available on each platform from December 21, 2020 until January 22, 2021. Google Forms was used to create the survey, which contains 34 questions, organized by themes, to facilitate understanding and response time.

\subsection{Survey Design and Sample}

Although there are dozens of social media platforms, Instagram was chosen for this study because the Ki et al. (2020) research, which reported that it is the primary platform for brand collaborations. A qualifier question about whether respondents use Instagram was created to ensure that the data captured were relevant to the research. If respondents answered no, they were thanked and did not participate in the survey. If they answered yes, they were allowed to continue to answer the rest of the survey questions. The survey yielded a total of 225 participants. Out of those $35(16 \%)$, respondents did not use Instagram, making the final sample size of 190 respondents. The respondents' sample consisted of Instagram users in the United States and abroad, intending to gather a reasonable representative sample that reflects the adult population in terms of age and gender. Participants were informed that the survey was completely anonymous and to be treated with confidentiality. Respondents of the survey are self-reported Instagram users ranging in age from 18 to 55 years old. However, the largest group of participants was predominantly 18 to 24 -year-olds, both female $(62 \%)$ and male $(36 \%)$, with a large majority having bachelor's degrees and residing in the U.S. The vast majority of participants indicated that they use Instagram at a frequency of several times per day. Table 1 summarizes demographic information of the individuals that participated in the study.

Table 1. Sample characteristics

\begin{tabular}{|c|c|c|c|}
\hline Demographics & Categories & $\mathrm{n}$ & $\%$ \\
\hline \multirow[t]{3}{*}{ Gender } & Male & 67 & 35.8 \\
\hline & Female & 115 & 61.5 \\
\hline & Prefer not to say & 5 & 2.7 \\
\hline \multirow[t]{6}{*}{ Age } & $18-24$ & 92 & 49.5 \\
\hline & $25-34$ & 38 & 21 \\
\hline & $35-44$ & 18 & 9.7 \\
\hline & $45-54$ & 22 & 11.8 \\
\hline & $55+$ & 6 & 3.2 \\
\hline & Prefer not to say & 8 & 4.8 \\
\hline \multirow[t]{7}{*}{ Ethnicity } & American Indian or Alaskan Native & 2 & 1.1 \\
\hline & Asian & 94 & 51.4 \\
\hline & Black or African American & 5 & 2.7 \\
\hline & Hispanic or Latino & 28 & 15.3 \\
\hline & White & 36 & 19.7 \\
\hline & Prefer not to say & 10 & 5.5 \\
\hline & Other & 8 & 4.4 \\
\hline \multirow[t]{4}{*}{ Education } & High School or Below & 17 & 9.7 \\
\hline & Bachelors Degree & 95 & 51.4 \\
\hline & Master of PhD & 63 & 34.1 \\
\hline & Prefer not to say & 9 & 4.9 \\
\hline \multirow[t]{6}{*}{ Household Income } & Less than $\$ 20,000$ & 23 & 12.6 \\
\hline & $\$ 20,000$ to $\$ 50,000$ & 31 & 16.9 \\
\hline & $\$ 50,000$ to $\$ 100,000$ & 36 & 19.7 \\
\hline & $\$ 100,000$ to $\$ 150,000$ & 14 & 7.8 \\
\hline & $\$ 150,000$ or more & 14 & 7.8 \\
\hline & Prefer not to say & 65 & 35.5 \\
\hline
\end{tabular}




\subsection{Measures}

Participants answered the survey (Appendix A), which included multiple-item measurement scales adapted from previous literature conducted by Dias et al. (2020) to ensure the measures' content validity. The online survey contained four sections: (1) Instagram Use, (2) Instagram Influencers, (3) Branding and Instagram during COVID-19, and (4) Demographic variables (age, gender, education, household income, and location). Individuals were asked questions measuring Instagram usage, frequency, brand behavior, and brand-influencer-follower relationship. Question formats include multiple-choice, Likert scale, and open-ended. The scales used five-point Likert-type response formats, in which respondents rated the content posted by influencers and brands from 1 ("not interested") to 5 ("extremely interested"). Additionally, respondents ranked their satisfaction with the behavior of influencers from 1 ("not satisfied") to 5 ("extremely satisfied"). The survey responses collected were analyzed using Microsoft Excel to understand the data better and highlight significant insights.

\section{Findings}

This study found that younger individuals, those in the 18 to 24-year-old age group, are more likely to follow influencers on Instagram regardless of the circumstance. Overall, we did not find that the pandemic affected the level of interaction with influencers amongst this group. As compared to the literature, we confirmed that Instagram users prefer authentic content from influencers and brands alike during crisis times and responded more positively to brands that changed their production in order to create products useful during the crisis. The results of the online survey are presented below.

\subsection{Instagram Usage}

Respondents were asked how often they used Instagram, as well as whether or not they follow influencers on the platform. Respondents reported using Instagram several times a day (65\%), twice a day $(8 \%)$, once a day (13\%), and a few times a week (13\%) respectively. This population uses Instagram mainly to keep in touch and follow the lives of friends and family (72\%), create, share or view stories $(66 \%)$, and create, share or view posts $(62 \%)$. As illustrated in Figure 1, when asked the question how users use Instagram, the majority of the respondents chose that they like to "follow the lives of my friends and relatives". Respondents also noted that they mostly create and share both posts and stories for their followers to view and view those of the individuals that they follow. The number of influencers followed by respondents varied widely.

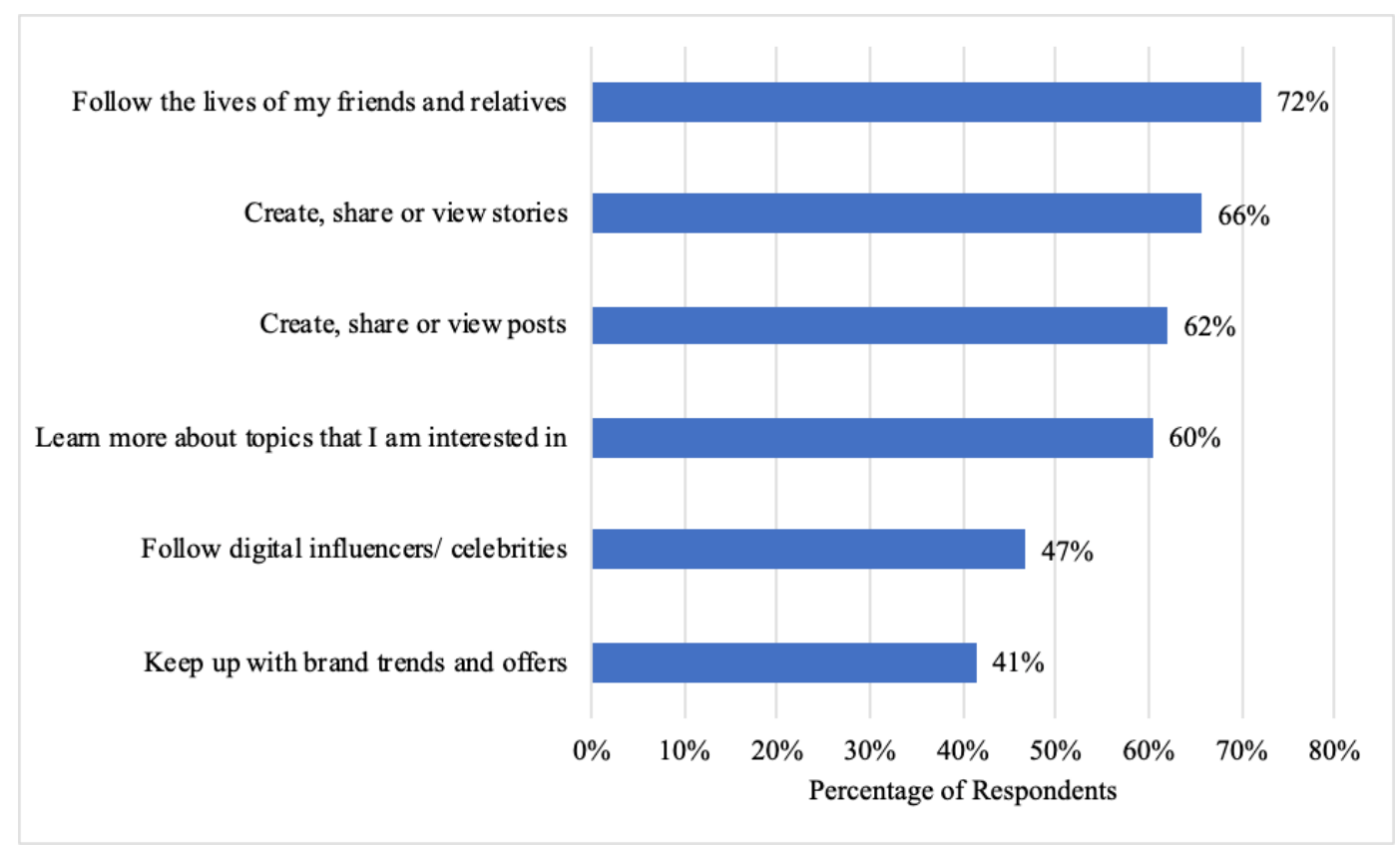

Figure 1. Instagram usage amongst the respondents 


\subsection{Influencer Marketing on Instagram}

As seen in Figure 2, when asked why individuals follow Instagram influencers, respondents noted type of content as a driver. Other important factors in choosing which influencers to follow are the lifestyle, personality, and values that the influencer has. This shows that interaction with followers and building a relationship is important to users. Regarding how individuals interact with influencers on Instagram, the majority of the respondents usually interact with likes. Some will also enjoy reacting to stories and commenting on the Influencer's page.

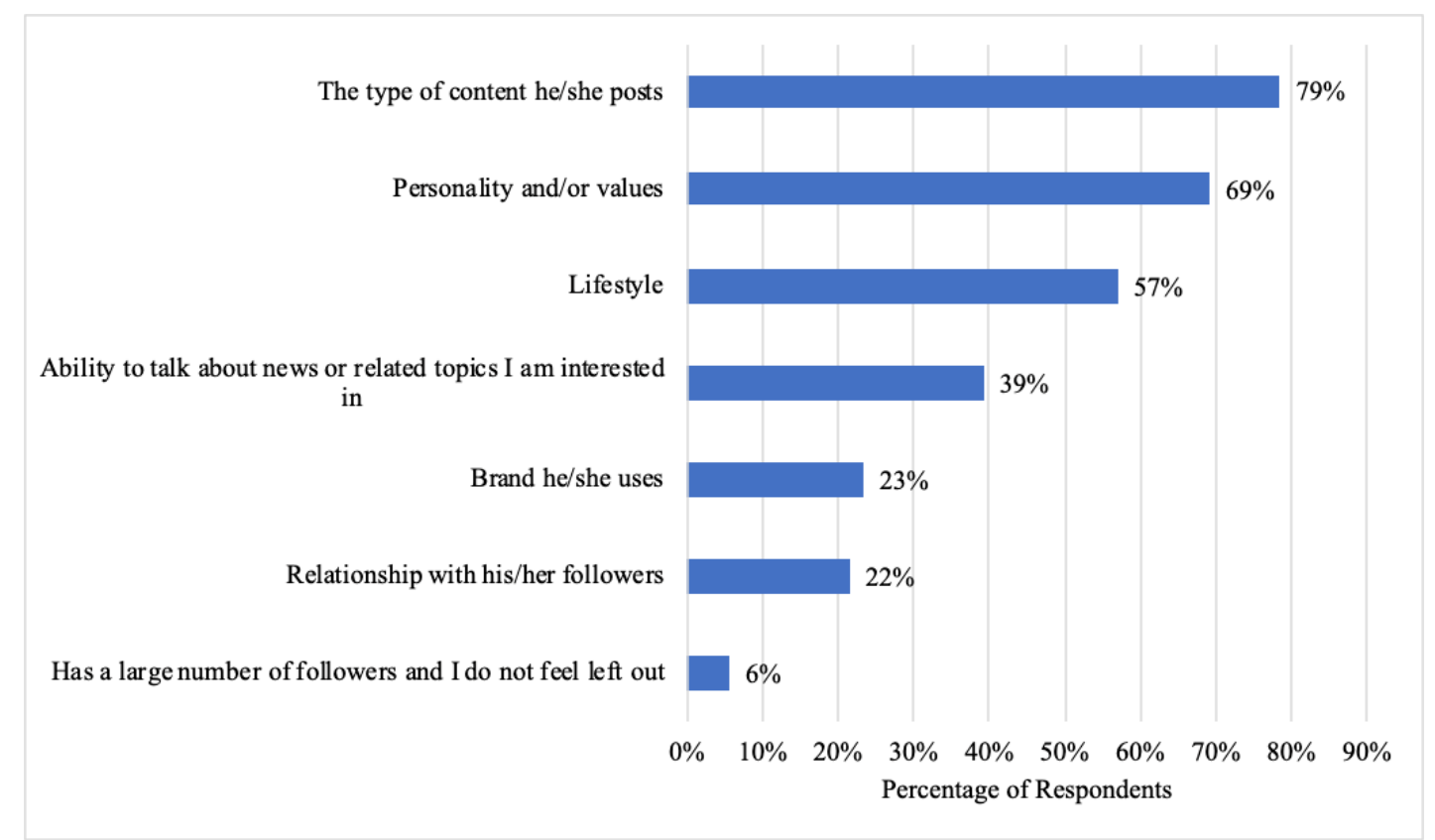

Figure 2. Reported reasons for following influencers

When asked how they interact with influencers, respondents indicated that "likes" was the primary form of interactions shown in Figure 3, followed by "reactions to stories" as a close second. 38\% of respondents reported that they have started following new digital influencers during the Covid-19 Pandemic. When asked why one individual responded that it was a "mood changer." Other individuals stated that following influencers helped them be "productive" and "motivated" during this time. Many expressed that following influencers helped them stay informed and learn useful tips on dealing with the pandemic. When asked what their opinion was about the relationship between brands and digital influencers many individuals had mixed opinions. Some respondents do not find the relationship to be authentic. Some respondents indicated that they do not "trust influencers' opinions and reviews" because they are being "paid" to promote good feedback. Other respondents suggested that influencers should do more "research" regarding the brands and products that they are sponsoring. Many people want to see advertisements that are from positive brands that have strong values. Other respondents do find this to be a positive relationship. Respondents indicated that this is a way of getting an "experienced opinion" about a product and they find that many influencers are "transparent" when reviewing and promoting the products. 


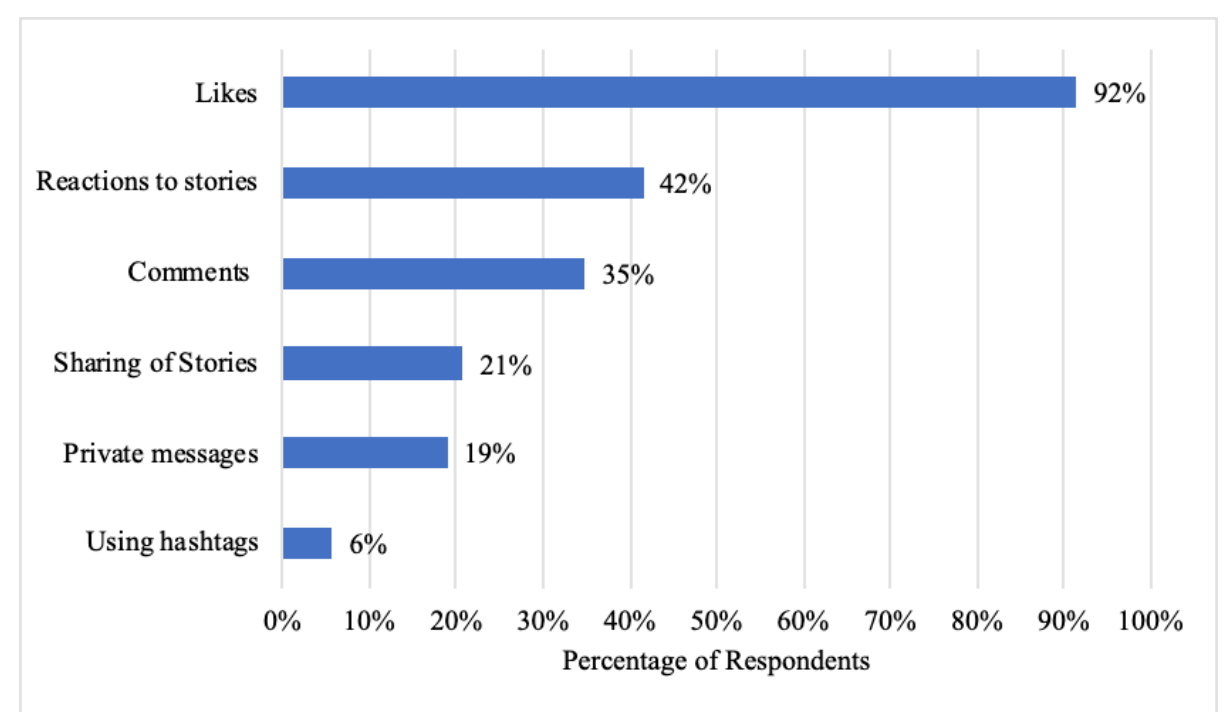

Figure 3. Respondents' interaction with influencers

The research question about the driving motivations for respondents to interact with influencers on Instagram found that a majority identifies "like the influencers post" as a primary motivation, as is shown in Figure 4. The influencers' perceived complementary attitudes and behaviors are closely motivated. Respondents also indicated that they follow influencers to find more information about the topics and brands of interest. These findings support insights gathered from a previous study conducted by Dias et al. (2020).

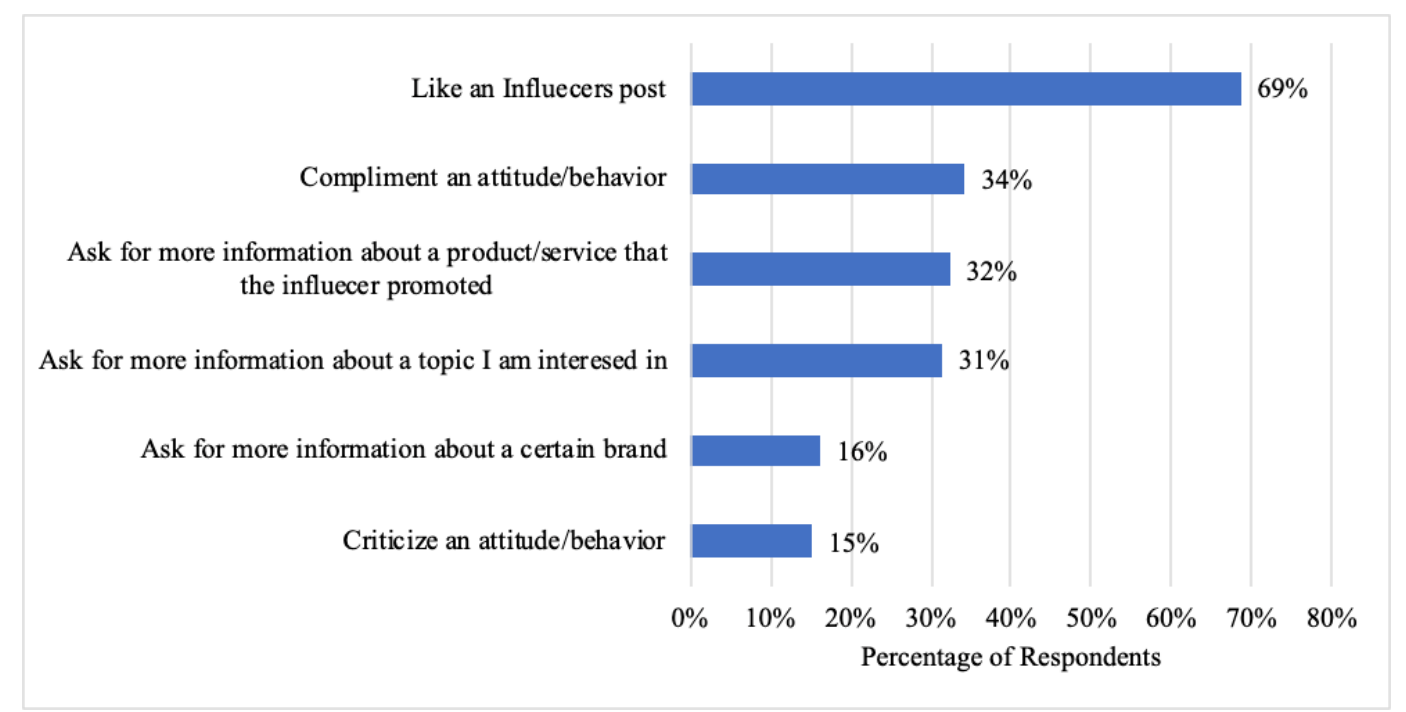

Figure 4. Respondent motivation to interact with influencers

In an effort to identify perceived advantages received from following influencers, respondents were asked to select from a list of options, as seen in Figure 5. In general, respondents in this group indicated that they view learning about new products/brands, keeping up with trends, and promotional codes as significant advantages received by consumers due to following influencers. This small insight is relevant. It indicates that consumers seem to be aware of influencer advertising and consider these influencers a source of information, and value the potential monetary savings. 


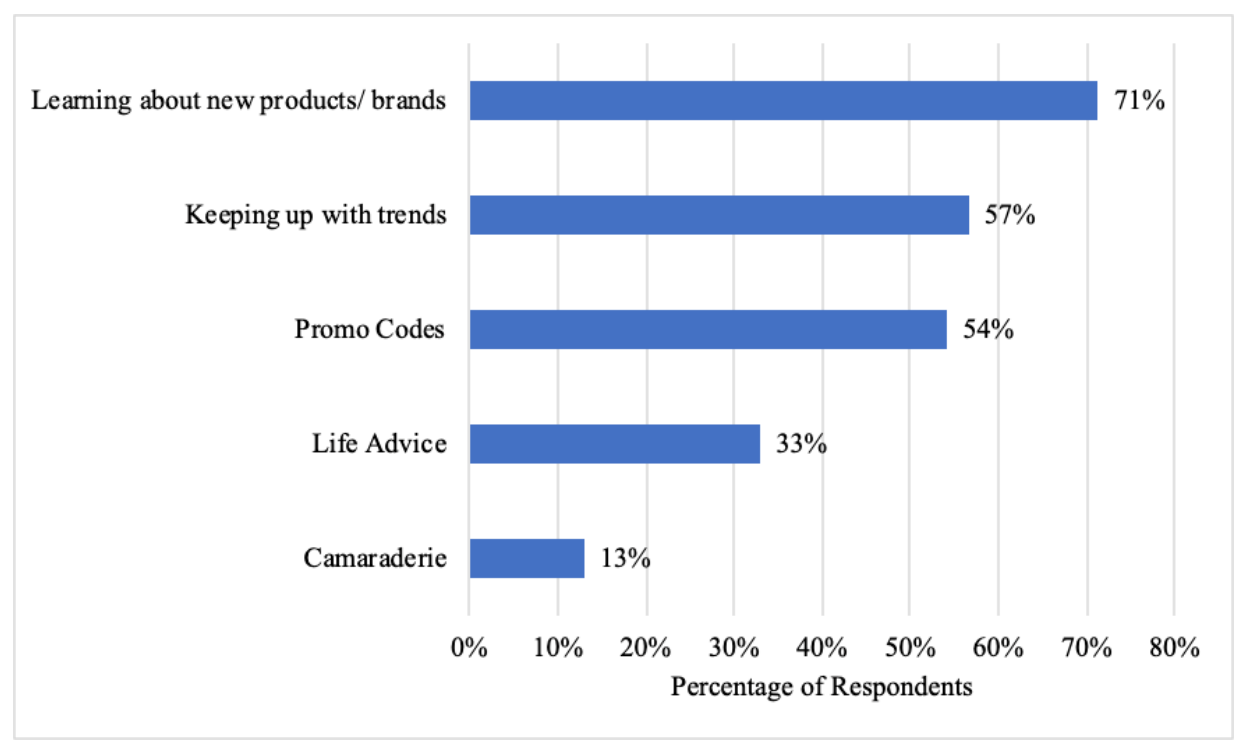

Figure 5. Reported advantages received from following an influencer

To determine the level of interest and satisfaction with the content posted by influencers on Instagram, respondents were asked to rank the following four content categories: stories about private lives, tutorials, tips/suggestions about products or services, inspiring photos and texts, based on a five-point Likert scale ranging from "not interested" to "extremely interested." As shown in Figure 6, this study found that more than $66 \%$ of respondents indicated having varying degrees of interest in content posted by influencers who shared stories about their private lives but were very interested in inspiring photos/quotes. This group also signaled a high level of interest for content about tips and suggestions of products/services available in the market. These segments consisted of the least number of respondents who were not interested in the mentioned contents. Additionally, although Instagram live seems to be an excellent way for the influencers to communicate with their community, most of the respondents did not seem interested in "live" events on the platform.

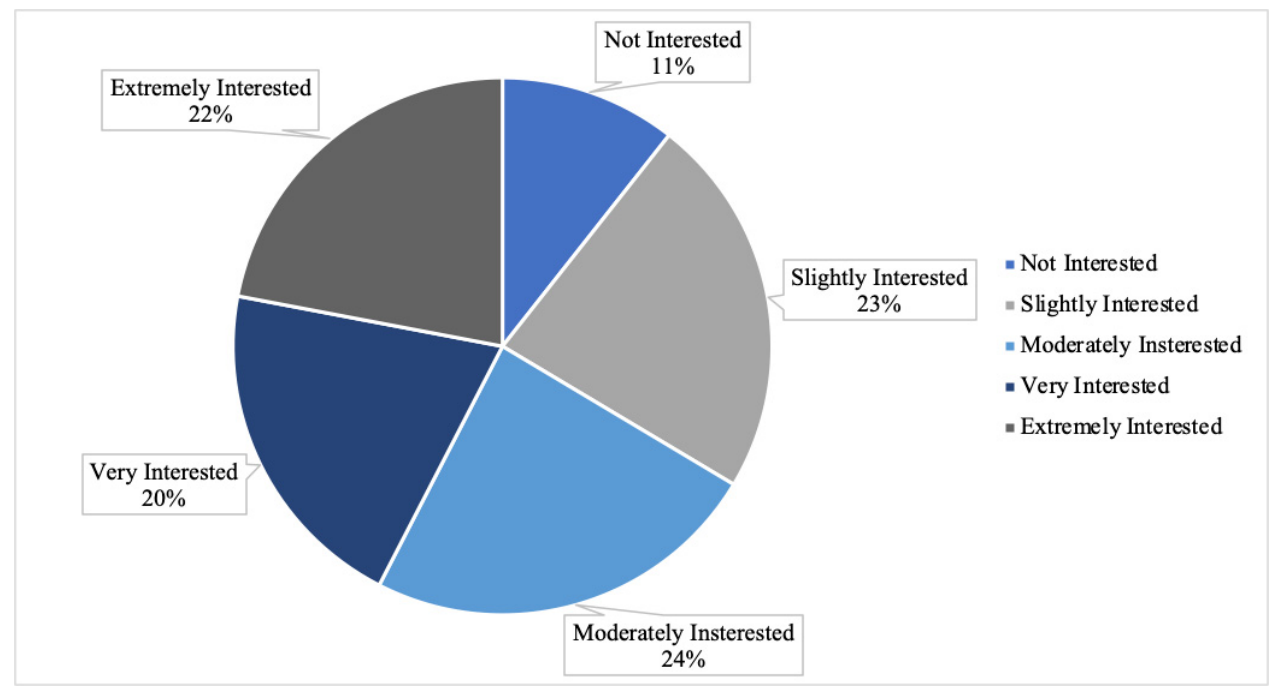

Figure 6. Graphical result of interest in content posted by influencers

Similarly, to determine the level of satisfaction with the behavior of influencers on the platform, respondents were asked to rank the following actions: creates artificial content/uses many filters, stops posting content that I like, always discloses when advertising brands/products, support a brand that does not represent their lifestyle, 
based on a five-point Likert scale ranging from "not satisfied" to "extremely satisfied." As shown in Figure 7, the most significant finding is that respondents indicated not being satisfied with influencers that create artificial content or that use too many filters. Additionally, respondents were not satisfied with influencers that stop posting content they like and that support brands that are not representative of their lifestyles/values. The results suggest that users are more likely to follow influencers that create genuine content which is consistent with previous literature.

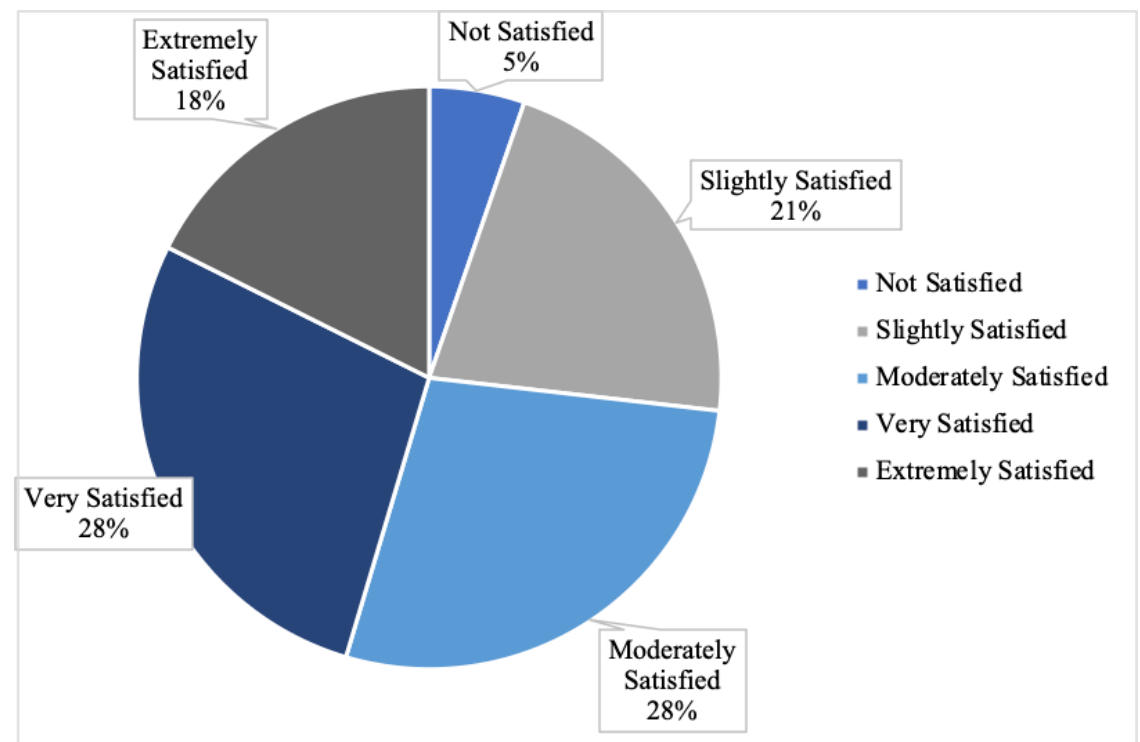

Figure 7. Graphical result of satisfaction of influencer behavior on Instagram

Lastly, many respondents also reported changes in how influencers communicate during the pandemic, as indicated in Figure 8. The most notable responses to the research questions regarding changes were "they have come up with new and innovative ways to interact with their audience." Some respondents noted that the "content changed to awareness and safety measures rather than usual topic" and "beside their regular contents, they helped share true and relevant information about the pandemic and about how to prevent the spreading of the virus." Others noted changes where the influencers they follow are now recognized as more authentic, open, and "real." Many acknowledge their privilege and be in fortunate positions. The perceived changes seem to have a positive impact on these respondents, increasing the influencer's credibility. This observation is essential for the brands they represent, especially if consumers believe that those influencers share the same principles as the brand. As noted in Dias et al. (2020), brands need to identify and partner with influencers perceived to have authenticity, personality, and the capacity for engagement to build a large following and thus increase brand awareness. 


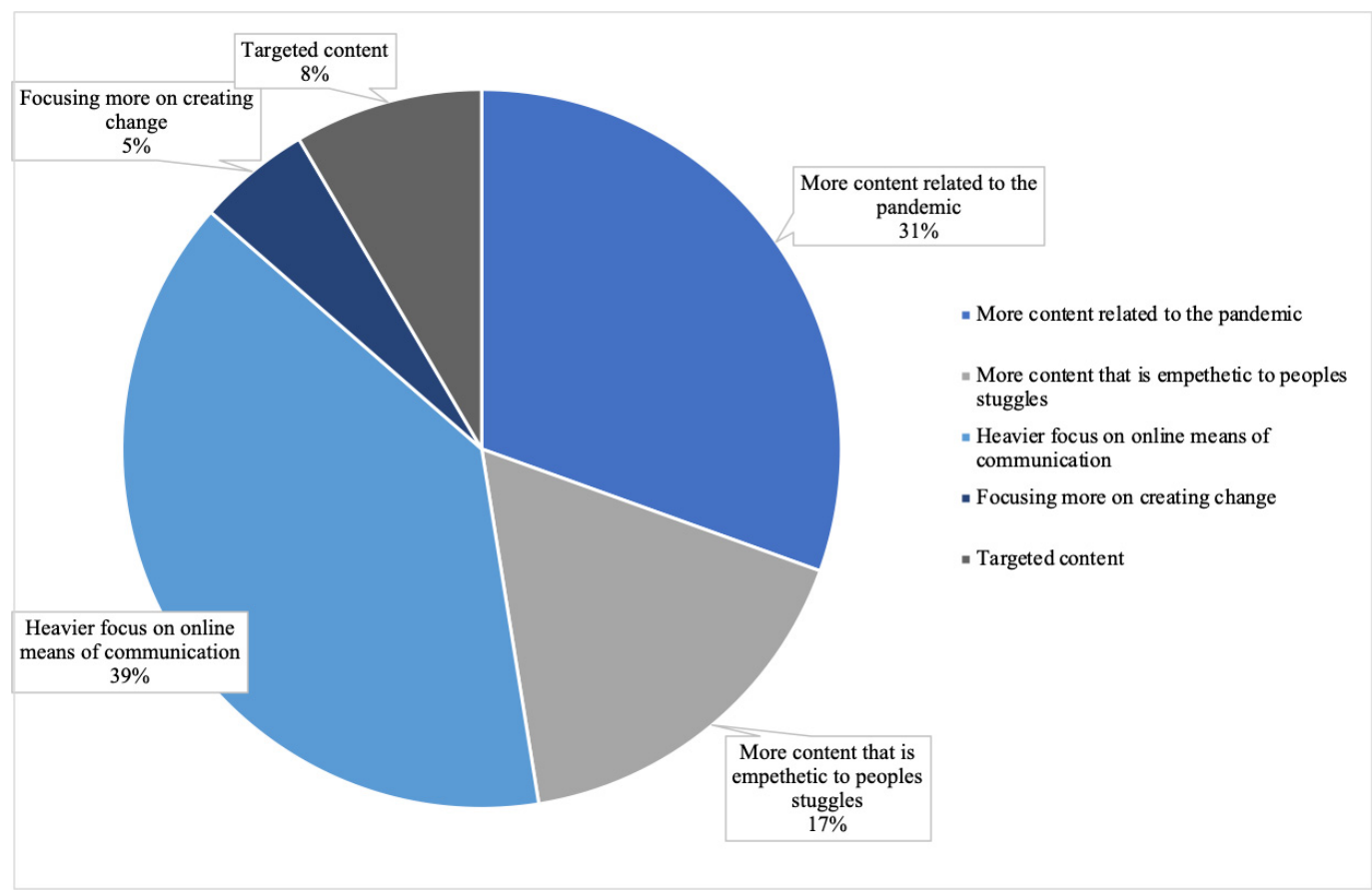

Figure 8. Graphical representation of influencer communication changes as noted by respondents

\subsection{Brand Communication and Relation with Influencers}

As for the relationship of Instagram users with their favorite brands, approximately $58 \%$ of respondents indicated that they followed brand accounts and continued to do so during this period. With a constant presence on Instagram, most respondents noted changes in communication by the brands they follow. Respondents indicated that brands are "more engaged with their followers," "all-digital, no personal," "more aggressive," and "focused on COVID precautions such as social distancing \& wearing masks." Due to the unprecedented circumstances of this pandemic, content preference differs slightly between the age groups as seen in Figure 9. Younger respondents reported a preference for brand content to "cheer up." Simultaneously, older groups lean slightly more towards more content about how brands adapted their products and services to be more useful during the pandemic. The younger group also demonstrated more interest in brand content supporting front-line professionals such as health professionals, police, and more. This could be due to younger respondents being more likely to follow the brands on Instagram and thus having a higher exposure level. Overall, this group has positively received the changes, which reaffirms the shifts in brands' strategies to communicate and engage with their consumers since the beginning of the pandemic. Additionally, this may also indicate a possible change in perspective by brands to address social responsibility roles in their communications and pursue a more strategic marketing approach on Instagram. 


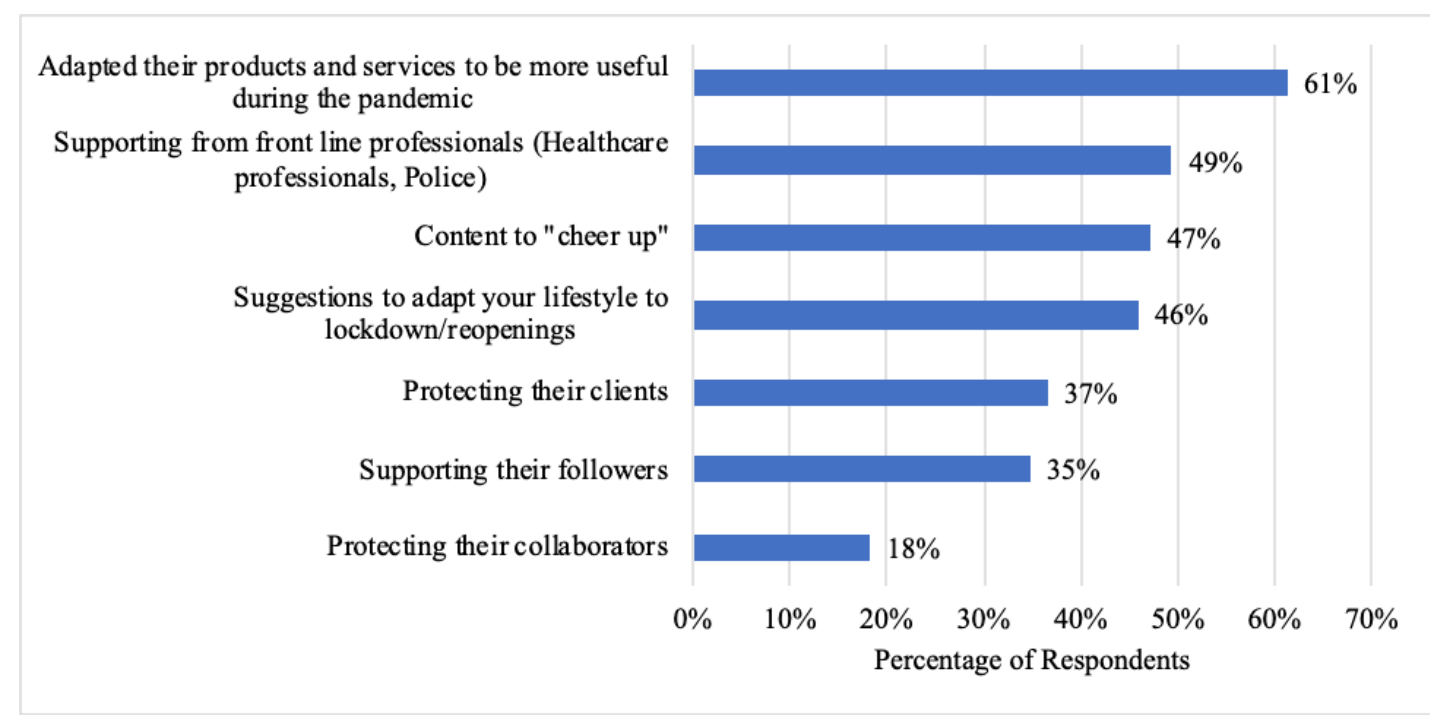

Figure 9. Brand content preferences as noted by respondents during this time

\section{Discussion}

Influencer marketing has emerged as a practical approach for brands to communicate and engage with their consumers. As the literature suggests, the relationship between influencers and brands can be mutually beneficial. This research found that younger Instagram users, those in the 18 to 24-year-old age group, are more likely to follow influencer accounts. This population is very aware of the relationship between those influencers and the brands they promote. Additionally, these respondents hold high regard and seek influencers that are transparent about the advertising of products and brands. There seems to be a correlation between perceived sharing of interests, characteristics, and behaviors with influencers and the emulation of those behaviors by their followers. We can speculate that the more similar a person feels with the influencer, the more trust they will have, and the more credible the influencer is perceived to be.

Consequently, perhaps, the more trust a person has for an influencer, the more willing they will be to purchase a recommended product or brand. The more an influencer shows how genuine they are, it would allow them to reach more people and persuade them to buy the products they are promoting. The research shows that more brands used influencers to market their products during the time of this pandemic. Many brands have had to also change their way of promotion by advocating the use of masks and social distancing. This period has allowed for more interaction between the brands and the customers on social media platforms. Brands have had to connect with influencers who are real and loyal to their followers to promote products and information that is factual. It is also crucial that influencers research the brands that they are asked to promote. It is vital to the users that when deciding which brands to work with influencers, examine the brand's values and mission. Testing products and deciding if they like the products is not enough; much of the population value honest companies and honest promotions. This is an important factor for both brands and influencers in influencer marketing, especially during difficult times, such as a pandemic that affects everyone.

\subsection{Limitations and Future Research}

This study has several limitations that point to multiple approaches for future research. Although there is a wide range of research on Instagram and influencer marketing, few studies on this specific topic made it more challenging to find information for this study to be more comparable. The first limitation is the actual sample size for this study, which is relatively small. Thus, it is not representative of the population and hinders the reliability of results. Given the lack of a representative sample, the findings may not generalize to other contexts. Future research may want to extend the work to specific age groups and market locations. Second, research was difficult to conduct due to limited data collection time constraints and participant responses' viability. Lastly, as trends continue to emerge, other platforms such as TikTok may be more appropriate to explore brand communications and the relationship with influencers during times of uncertainty or crisis.

\section{References}

Argyris, Y. A., Wang, Z., Kim, Y., \& Yin, Z. (2020). The effects of visual congruence on increasing consumers' brand engagement: An empirical investigation of influencer marketing on instagram using deep-learning 
algorithms for automatic image classification. Computers in Human Behavior, 112, 106443. https://doi.org/10.1016/j.chb.2020.106443

Arora, A., Bansal, S., Kandpal, C., Aswani, R., \& Dwivedi, Y. (2019). Measuring social media influencer index-insights from facebook, Twitter and Instagram. Journal of Retailing and Consumer Services, 49, 86-101. https://doi.org/10.1016/j.jretconser.2019.03.012

Campbell, C., \& Farrell, J. R. (2020). More than meets the eye: The functional components underlying influencer marketing. Business Horizons, 63(4), 469-479. https://doi.org/10.1016/j.bushor.2020.03.003

Dhanesh, G. S., \& Duthler, G. (2019). Relationship management through social media influencers: Effects of followers' awareness of paid endorsement. Public Relations Review, 45(3), 101765. https://doi.org/10.1016/j.pubrev.2019.03.002

Dias, P., Pessôa, C., \& Andrade, J. G. (2020). Brand Communication on Instagram during the COVID-19 Pandemic: Perceptions of users and brands. International Association for Media and Communication Research. Retrieved from https://repositorium.sdum.uminho.pt/bitstream/1822/66143/1/2923.pdf

Djafarova, E., \& Bowes, T. (2020). 'Instagram Made Me Buy It': Generation Z Impulse Purchases in Fashion $\begin{array}{llllll}\text { Industry. Journal of Retailing and Consumer } & \text { Services, } & 102345 .\end{array}$ https://doi.org/10.1016/j.jretconser.2020.102345

Enberg, J. (2020, August 24). Influencer Marketing in the Age of COVID-19. Insider Intelligence. Retrieved from https://www.emarketer.com/content/influencer-marketing-in-the-age-of-covid-19

Ha, S., Huang, R., \& Park, J. (2019). Persuasive brand messages in social media: A mental imagery processing perspective. Journal of Retailing and Consumer Services, 48, 41-49. https://doi.org/10.1016/j.jretconser.2019.01.006

Jin, S. V., \& Ryu, E. (2020). "I'll buy what she's \#wearing": The roles of envy toward and parasocial interaction with influencers in Instagram celebrity-based brand endorsement and social commerce. Journal of Retailing and Consumer Services, 55, 102121. https://doi.org/10.1016/j.jretconser.2020.102121

Ki, C.-W. C., Cuevas, L. M., Chong, S. M., \& Lim, H. (2020). Influencer marketing: Social media influencers as human brands attaching to followers and yielding positive marketing results by fulfilling needs. Journal of Retailing and Consumer Services, 55, 102133. https://doi.org/10.1016/j.jretconser.2020.102133

Maares, P., Banjac, S., \& Hanusch, F. (2020). The Labour of Visual Authenticity on Social Media: Exploring Producers' and Audiences' Perceptions on Instagram. Poetics, 101502. https://doi.org/10.1016/j.poetic.2020.101502

Phua, J., Jin, S. V., \& Kim, J. (2017). Gratifications of using Facebook, Twitter, Instagram, or Snapchat to follow brands: The moderating effect of social comparison, trust, tie strength, and network homophily on brand identification, brand engagement, brand commitment, and membership intention. Telematics and Informatics, 34(1), 412-424. https://doi.org/10.1016/j.tele.2016.06.004

Tafesse, W., \& Wood, B. P. (2020). Followers' engagement with instagram influencers: The role of influencers' content and engagement strategy. Journal of Retailing and Consumer Services, 58, 102303. https://doi.org/10.1016/j.jretconser.2020.102303

\section{Appendix A}

\section{Supplementary data}

\section{Instagram and Influencer Marketing During COVID-19 Pandemic Online Survey}

1. Do you use Instagram?
Yes
No

2. How frequently do you use Instagram?
A few times a week
Once a day
Twice a day
Several times a day 
3. How do you use Instagram? Select all that apply

Create, share or view posts

Create, share or view stories

Follow the lives of my friends and relatives

Learn more about topics that I am interested in

Learn more about topics that I am interested in

Keep up with brand trends and offers

4. Do you follow Instagram Influencers?
Yes
No

5. Who are your 3 favorite Instagram influencers?

6. What reasons make you follow an Instagram influencer? Select all that apply
Lifestyle
Personality and/or values
Brands he/she uses
The type of content he/she posts
Relationship with his/her followers

Ability to talk about news related to topics I am interested in

Has a large number of followers and I don't feel left out

7. How do you interact with influencers on Instagram? Select all that apply.
Likes
Reactions to stories
Sharing of stories
Comments
Private messages
Using Hashtags

8. Which of the following has motivated you to interact with a digital influencer? Select all that apply.

Like an influencers post

Compliment an attitude/behavior

Criticize an attitude/behavior

Ask for more information about a topic I am interested in

Ask for more information about a product/service that the influencer promoted

Ask for more information about a certain brand

9. How interested are you in the type of content that digital influencers post? On a scale of not interested; 2-slightly interested; 3-moderately interested; 4-very interested; 5-extremely interested.

Stories about their private lives

Tutorials

Tips/suggestions about products or services

Inspiring photos and/or texts

Lives about any event or activity

10. How satisfied are you with the types of content that digital influencers post? On a scale of not interested; 2-slightly interested; 3-moderately interested; 4-very interested; 5-extremely interested, select all that apply. 
Stories about their private lives

Tutorials

Tips/suggestions about products or services

Inspiring photos and/or texts

Lives about any event or activity

11. How satisfied are you with certain behaviors of digital influencers? On a scale between — not satisfied; 2-slightly satisfied; 3-moderately satisfied; 4-very satisfied; 5 - extremely satisfied, select all that apply.

Creates artificial content, uses many filters

Doesn't answer comments

Stops posting content that I like

Promotes brands that I don't like

Always discloses when advertising brands or products

Compliments and/or interacts with followers

Supports brands that don't fit his/her lifestyle or values

12. Have you purchased products/services because of a digital influencer?
Yes
No

13. Have you promoted a brand or product that you became aware of through a digital influencer on your Instagram profile?

Yes
No

14. Have you felt that the digital influencers that you follow changed their communication on Instagram during the Covid-19 pandemic?
Yes
No

15. Have you started following any new digital influencer during the Covid-19 pandemic?
Yes
No

16. If yes, who and why?

17. How has influencer communication changed?

18. Did those changes please you?
Yes
No

19. Do you follow your favorite brands on Instagram?
Yes
No

20. What topics did you prefer that brands talked about during this period? Select only top THREE.

Content to "cheer up"

How they are protecting their collaborators

How they are protecting their clients

How they have adapted their products and services to be more useful during the pandemic

Suggestions to adapt your lifestyle to lockdown/un-lockdown

Supporting their followers 
Supporting front line professionals (Health professionals, Police, etc.)

21. What is your opinion about the relationship between brands and digital influencers?

22. What are the advantages you feel that consumers receive when following Influencers? Select all that apply.

Promo codes

Life advice

Learning about new products/brands

Camaraderie

Keeping up with trends

23. Do you value brands that have continued to support the influencers they worked with, even if their content is more limited due to the pandemic?
Yes
No

24. Have you felt that brands that you follow changed their communication on Instagram during the Covid-19 pandemic?
Yes
$\square \quad$ No

25. How has communication changed?

26. Did those changes please you?
Yes
No

27. What is your age?
18 to 24
25 to 34
35 to 44
45 to 54
$55+$
Prefer not to say

28. What is your gender?
Female
Male
Prefer not to say

29. What is your ethnicity?

American Indian or Alaskan Native

Asian

Black or African American

Hispanic or Latino

Native Hawaiian or other Pacific Islander

White

Prefer not to say

30. What is your Education level?

High School or below

Bachelor's Degree

Master or $\mathrm{PhD}$ 
Prefer not to say

31. What is your household income?

$\square \quad$ Less than $\$ 20,000$

$\square \quad \$ 20,000$ to $\$ 50,000$

$\square \quad \$ 50,000$ to 100,000

$\square \$ 100,000$ to $\$ 150,000$

$\square \$ 150,000$ or More

$\square \quad$ Prefer not to say

32. Do you reside in the US?

33. In what state or U.S. territory do you reside?

34. What is your country of residence?

\section{Copyrights}

Copyright for this article is retained by the author, with first publication rights granted to the journal.

This is an open-access article distributed under the terms and conditions of the Creative Commons Attribution license (http://creativecommons.org/licenses/by/4.0/). 